\title{
CONCEPÇÕES E PERCEPÇÕES DOS TÉCNICOS ADMINISTRATIVOS EM EDUCAÇÃ̃O ACERCA DA INCLUSÃO DE PESSOAS COM NECESSIDADES EDUCACIONAIS ESPECÍFICAS NA EDUCAÇÃO PROFISSIONAL E TECNOLÓGICA
}

\author{
Conceptions and Perceptions of Administrative Technicians in Education about \\ Inclusion of People with Specific Educational Needs in Professional and Technological \\ Education
}

\author{
Hérlei Mariano Martins Alves ${ }^{1}$ \\ Géssika Cecília Carvalho ${ }^{2}$
}

\begin{abstract}
Resumo: O presente estudo teve como objetivo analisar as concepções e percepções dos Técnicos Administrativos em Educação quanto à inclusão de estudantes com Necessidades Educacionais Específicas na Educação Profissional e Tecnológica. A pesquisa se insere numa abordagem qualitativa. Os dados foram coletados por meio de questionário semiestruturado, aplicado com os 24 técnicos administrativos que compõem o quadro efetivo de um campus do Instituto Federal de Alagoas, por meio da plataforma online Google Forms. Com base na análise dos resultados, depreende-se que os técnicos administrativos são atores sociais relevantes à disseminação dos valores construídos no ambiente escolar, de tal modo que suas práticas podem somar-se às dos demais profissionais, visando à consolidação de um projeto educacional inclusivo, que transcende a sala de aula e a relação professor-aluno, para acontecer em todos os espaços e na interação com todos os que compõem as instâncias administrativas e pedagógicas da instituição. Concluiu-se, entretanto, que existe uma demanda de formação em educação inclusiva para esses profissionais, tendo em vista a superação do modelo educacional que secundariza e invisibiliza a participação dos técnicos na construção de práticas educativas inclusivas.
\end{abstract}

Palavras-chave: Inclusão. Formação integrada. Técnico Administrativo em Educação.

\begin{abstract}
The present study aimed to analyze the conceptions and perceptions of administrative technicians in education regarding the inclusion of students with Specific Educational Needs in Professional and Technological Education. The research is part of a qualitative approach. The data were collected through a semi-structured questionnaire, applied to the 24 administrative technicians who make up the effective staff of a campus of the Federal Institute of Alagoas, through the online platform Google Forms. Based on the analysis of the results, it appears that administrative technicians are social actors relevant to the dissemination of values built in the school environment, in such a way that their practices can be added to those of other professionals, aiming at the consolidation of an inclusive educational project, which transcends the classroom and the teacher-student relationship, to happen in all spaces and in the interaction with all who compose the administrative and pedagogical instances of the

\footnotetext{
${ }^{1}$ Mestra em Educação Profissional e Tecnológica pelo Instituto Federal de Alagoas (ProfEPT/Ifal). Técnica em Assuntos Educacionais na Universidade Federal de Alagoas (UFAL). ORCID: https://orcid.org/0000-00020716-170X Email: herlei.alves@ santana.ufal.br

${ }^{2}$ Doutora em Sociologia pela Universidade Federal da Paraíba (UFPB). Docente efetiva no Instituto Federal de Alagoas (IFAL). ORCID: https://orcid.org/0000-0002-3178-0711 E-mail: gessika.silva@ifal.edu.br
} 
institution. It was concluded, however, that there is a demand for training in inclusive education, specific to these professionals, with a view to overcoming the educational model that makes secondary and invisible the participation of technicians in the construction of inclusive educational practices.

Keywords: Inclusion. Integrated training. Administrative Technicians in Education.

\section{Introdução}

No decurso da história, diferentes paradigmas exerceram influência no domínio da percepção educacional sobre as pessoas com Necessidades Educacionais Específicas (NEE). Marcadamente, a predominância do pensamento médico e, mais recentemente, o resgate pedagógico da educação inclusiva, são modelos que contribuíram para a construção das concepções inerentes ao movimento de inclusão e exclusão das pessoas com NEE e seu acesso à educação.

Nesse contexto, destacamos o papel dos Institutos Federais de Educação Profissional, Científica e Tecnológica, pertencentes à Rede Federal de Educação Profissional, Científica e Tecnológica (RFEPCT), que optaram pelo paradigma da educação inclusiva e, desde então, buscam estratégias para consolidar uma abordagem inclusiva de educação profissional, comprometida com a construção da cidadania e a inserção de alunos com NEE numa sociedade contemporânea marcada, sobretudo, por rápidas e profundas transformações.

Nesse sentido, os Institutos Federais buscam imprimir, na educação profissional, as marcas da educação inclusiva, notadamente, o reconhecimento, a aceitação e a ressignificação da postura diante das diferenças, na medida em que as acolhe e as vê como possibilidade de crescimento à aprendizagem de todos. Tal esforço e compromisso pertence à comunidade educacional em geral, de modo que gestores, docentes e técnicos administrativos, estejam inseridos na criação e na reestruturação das condições didático-pedagógicas e de infraestrutura da instituição para a construção de uma educação inclusiva.

O contexto de crescente demanda de estudantes com Necessidades Educacionais Específicas na Rede Federal de Educação e na Educação Profissional, graças ao sucesso das políticas públicas no sentido de garantir o acesso deste alunado à educação, impõe, igualmente, a necessidade da garantia de espaços de diálogos e implementação de ações formativas à comunidade escolar em geral, incluindo os Técnicos Administrativos em Educação.

Nessa direção, empreendemos, em sites como Google Acadêmico, Scielo e CAPES, a busca pela temática relativa à formação de Técnicos Administrativos em Educação para contribuírem na construção de práticas educativas inclusivas na instituição escolar, todavia os resultados revelaram-se insipientes, comparados ao quantitativo de produções acadêmicas centradas na formação de docentes e gestores. Sinalizamos, dessa forma, o papel irrelevante que tem sido atribuído aos técnicos administrativos no que tange ao processo de inclusão de alunos com NEE, limitando a participação e as contribuições desses profissionais para a consolidação de práticas educativas inclusivas no cotidiano da instituição. O presente debate justifica-se pela necessidade de sensibilização e visibilização desses profissionais da educação.

Sem embargo, podemos questionar quem são realmente esses profissionais da educação. A esse respeito, Navarro et al. (2006, p.11) referem que "[...] seu elemento de identificação, nitidamente perceptível, está no fato de serem todos sujeitos, por intermédio do exercício do seu trabalho, da efetivação social do ato educativo escolar". Assim sendo, compreendemos que 
o papel desempenhado pelos servidores técnicos administrativos, nos diversos cargos e funções dos Institutos Federais, é relevante para oferecer o suporte necessário ao objetivo maior da instituição, a saber, a formação integrada de todos os alunos, independentemente das necessidades individuais que apresentem.

Diante do exposto, a pesquisa norteia-se pelo seguinte problema: quais são as concepções e as percepções dos Técnicos Administrativos em Educação sobre a inclusão de pessoas com Necessidades Educacionais Específicas no contexto da Educação Profissional e Tecnológica? Assim, teve como objetivo analisar as concepções e percepções dos Técnicos Administrativos em Educação quanto à inclusão de estudantes com Necessidades Educacionais Específicas na Educação Profissional e Tecnológica. Os instrumentos para coleta de dados consistiram em questionários semiestruturados aplicados com 24 técnicos administrativos de um campus do Instituto Federal de Alagoas (Ifal), em junho de 2020.

\section{Referencial Teórico}

Nesta seção, refletimos sobre o paradigma da inclusão de alunos com NEE, a partir do princípio de formação integrada assumido pela RFEPCT, bem como sobre o papel dos técnicos administrativos e sua relação com as práticas inclusivas na Educação Profissional e Tecnológica (EPT).

\subsection{A Formação integrada a serviço do processo de inclusão nos Institutos Federais}

A Lei ${ }^{\circ} 11.892 / 2008$ representa uma reconfiguração da rede de educação profissional, sob o ponto de vista organizacional e institucional. A criação de 38 Institutos Federais de Educação Profissional, Científica e Tecnológica (IFs) representa uma nova institucionalidade, manifestada na criação da Rede Federal de Educação Profissional, Científica e Tecnológica (RFEPCT). Nascida sob os fundamentos de uma educação cidadã e como resultado da luta encampada por educadores progressistas, a rede federal rompe com o paradigma de uma formação predominantemente tecnicista e fragmentada, voltada, exclusivamente, ao domínio das habilidades para inserção do indivíduo no mercado de trabalho, tendo como objetivo a promoção de uma formação integrada, embasada nos princípios da educação politécnica e omnilateral. Ciavatta e Ramos (2011) assim definem a formação integrada:

\footnotetext{
Trata-se de constituir o ensino médio como num processo formativo que integre as dimensões estruturantes da vida, trabalho, ciência e cultura, abra novas perspectivas de vida para os jovens e concorra para a superação das desigualdades entre as classes sociais. (CIAVATTA; RAMOS, 2011, p. 23).
}

A educação politécnica, ancorada numa visão dilatada do trabalho como princípio educativo geral, visa à integração de todas as dimensões que constituem a vida humana, a saber, ciência, cultura e trabalho, preconizando assim, a formação omnilateral do indivíduo, necessária à dissociação da formação educativa das demandas mercadológicas, concebendo a educação como "caminho para a produção da vida" (RAMOS, 2008, p. 4). Nesse sentido, tendo em vista as contribuições de Saviani (2003), o aluno está inserido na perspectiva da omnilateralidade, visto, portanto, para além da formação restrita à vida produtiva. Diante disso, nossa investigação parte do pressuposto de que o processo de ensino, no contexto da EPT, deve ser balizado para realçar as potencialidades do estudante com NEE, que numa tradição de ensino 
formal, acabaram por ter seu acesso à educação alijado.

O projeto de educação integrada propõe uma formação mais ampla do sujeito, que prepara para o mundo do trabalho, mas também para a vida, implicando novas possibilidades para a inclusão de alunos com NEE, ao possibilitar que os sujeitos, independentemente de suas necessidades educacionais, sejam inseridos na vida em sociedade, o que atua para a efetivação de uma sociabilidade com maior equidade. Na travessia para essa organização social menos desigual, o conceito de formação omnilateral contribui para a superação das práticas excludentes no campo da educação que, no decurso da história, moldaram as práticas educativas para o atendimento das demandas capitalistas, aprofundando a exclusão dos alunos com NEE.

Diante desse contexto, a inclusão na EPT compreende ultrapassar a ótica unilateral, entendendo o sujeito para além de uma dimensão que, em tese, o integraria ao mundo do trabalho. Por este ângulo, os Institutos Federais vêm implementando políticas de ações afirmativas que contribuem para o acesso, a permanência e o êxito dos estudantes com NEE, visando à distribuição mais equitativa dos bens materiais e culturais advindos do processo de formação.

O paradigma educacional da RFEPCT considera a dívida histórica em relação às classes sociais desfavorecidas e aos grupos minoritários, entre os quais as pessoas com NEE, e busca estratégias para minimizar os impactos da desigualdade e da marginalidade. Nessa direção, os Institutos Federais vinculam suas ações ao objetivo da permanência e êxito dos estudantes com NEE. O Programa de Educação, Tecnologia e Profissionalização para Pessoas com Necessidades Específicas - TEC NEP - prevê a criação dos Núcleos de Atendimento às Pessoas com Necessidades Educacionais Específicas (NAPNE), que representam um marco na inclusão de alunos com NEE, tendo em vista a orientação para que sejam implantados na estrutura organizacional de todos os Institutos Federais, ampliando, sobremaneira, os espaços educativos inclusivos.

No âmbito do Ifal, a implementação do NAPNE constitui-se espaço potencial à promoção de ações inclusivas sistemáticas, sendo regulamentado pela Resolução 45/14, que dispõe sobre sua organização, funcionamento e atribuições. Assim, dentre as suas atribuições constam "o fomento às políticas de acesso, permanência e êxito dos estudantes com NEE e a promoção de eventos que promovam a sensibilização da comunidade acadêmica e capacitação de servidores em geral" (IFAL, 2014, p. 4). Na busca pela inclusão, o NAPNE apresenta-se como possibilidade à conscientização coletiva, à internalização de conceitos e valores, à quebra de barreiras e à solidificação de novas posturas relacionadas ao movimento da inclusão.

O modelo de formação integrada é o caminho para favorecer um projeto educativo inclusivo que oportuniza ao aluno com NEE o acesso à ciência, à cultura e à preparação para o trabalho. Sob essa configuração, a formação de alunos com NEE transcende o caráter meramente físico da inserção e se materializa baseada nos princípios da inclusão social. Nessa perspectiva, a premissa de uma educação integrada se coloca como opção viável para superar a formação dual, fragmentada, utilitarista, que historicamente caracterizou a educação brasileira destinada aos filhos da classe trabalhadora e aos grupos minoritários, dentre os quais, as pessoas com NEE. Sob uma premissa de formação para a dimensão do trabalho em seus sentidos ontológico e histórico, a educação integral amplia as oportunidades, diminui as desigualdades e favorece a inclusão educacional e social do aluno com NEE.

Ressaltamos, todavia, que a proposta de uma educação integrada e inclusiva requer sensibilização e conscientização por parte de todos os agentes envolvidos no projeto educacional da instituição escolar, incluindo aqueles que não estão diretamente envolvidos com a dimensão do ensino. Nesse sentido, convém refletirmos sobre o importante papel 
desempenhado pelos técnicos administrativos à consolidação de paradigmas mais inclusivos no âmbito da EPT.

2.2 O papel dos Técnicos Administrativos em Educação e sua relação com as práticas inclusivas na EPT

A crescente demanda de alunos com NEE é, hoje, uma realidade nos Institutos Federais, em parte pela execução das políticas públicas destinadas à garantia do acesso e permanência destes alunos à educação. Dentre essas políticas, destacamos a formação e a valorização profissional dos servidores técnico-administrativos, enquanto estratégia relevante para promover a defesa dos direitos humanos, bem como a eliminação de todas as formas de discriminação e preconceito, culminando em uma instituição mais plural, ética e justa.

A reflexão acerca do papel desempenhado pelos servidores técnico-administrativos e sua relação com as práticas inclusivas na EPT, vincula-se ao objetivo maior que consiste em criar espaços de diálogos para sensibilizar esses educadores à participação e ao envolvimento com a problemática da inclusão, visando ao aprimoramento do olhar sobre o estudante com NEE e à aproximação com o seu universo. Desse modo, ressaltamos que a atuação do técnico administrativo em um ambiente fora da sala de aula, mas ainda assim, no ambiente escolar, concorre para a melhoria dos processos educativos em EPT, contribuindo na formação integral dos estudantes.

Conforme o pensamento de Sassaki (1997), acreditamos que os técnicos administrativos podem contribuir, sobretudo, na quebra de barreiras atitudinais, que dizem respeito à construção de atitudes despidas de preconceitos, estigmas, estereótipos e discriminações. Advogamos, pois, pela reflexão dos profissionais da educação em favor de uma educação que respeite a singularidade do aluno e estabeleça objetivos mais ligados às possibilidades de desenvolvimento de cada um, não apenas no aspecto da aprendizagem cognitiva, mas afetiva e de relação interpessoal.

Nesse sentido, vislumbramos, como horizonte possível, a criação de espaços de diálogos que, ao inserir os servidores técnico-administrativos, promovam um amplo debate sobre o compromisso coletivo na construção de uma escola plural, diversa e inclusiva. Acreditamos que políticas institucionais, com tal direcionamento, são uma possibilidade para promover o acesso ao conhecimento sobre a educação inclusiva, fortalecendo as ações que conduzem ao melhor atendimento do estudante com NEE, bem como para disseminar a temática da inclusão à categoria dos técnicos administrativos, tendo em vista a importância da atuação de todos os profissionais na busca de pressupostos para uma educação inclusiva.

\section{Metodologia}

A pesquisa se insere numa abordagem qualitativa, na medida em que se presta à interpretação dos fenômenos de natureza social, notadamente aos problemas manifestados no campo educacional. Compreendemos que a abordagem qualitativa nos ajuda a captar o universo das relações traçadas nas escolas e a propor soluções para tais questões, antes ocultadas nas análises exclusivamente quantitativas (LUDKE; ANDRÉ, 1986). A escolha do campus do Ifal, lócus para realização da pesquisa, foi feita com base no conhecimento da realidade local, por meio do qual identificamos o seguinte problema: a partir da lei $n^{\circ} 12.711 / 12$, que prevê um percentual de vagas para pessoas com deficiência nos processos seletivos das instituições federais de ensino, o campus passou a receber com mais frequência alunos com NEE. Diante 
do exposto, percebeu-se a necessidade de fortalecer as práticas inclusivas, a fim de promover a efetiva inclusão educacional de alunos com NEE.

Os critérios de inclusão desse estudo consideraram participantes da pesquisa os técnicos administrativos em educação, dos gêneros masculino e feminino, que eram parte do quadro efetivo da instituição lócus da pesquisa em junho de 2020. O universo da pesquisa apresenta uma totalidade de 24 participantes. Os instrumentos para coleta de dados consistiram em questionários semiestruturados aplicados com 24 técnicos administrativos de um campus do Instituto Federal de Alagoas (Ifal), em junho de 2020. O questionário constituiu-se de uma combinação entre 10 (dez) questões abertas e fechadas e foi aplicado pela plataforma on-line Google Forms.

Após a coleta dos dados, efetuou-se a interpretação dos dados, à luz da análise qualitativa. De início, em atenção ao que propõem Ludke e André (1986), organizou-se o material coletado para uma análise crítico-reflexiva. Em seguida, examinaram-se as informações considerando o contexto e a realidade do universo pesquisado, que, neste caso, apresentam as concepções e percepções dos TAEs em relação à temática da inclusão. Minayo (2012) ressalta que a análise dos dados não deve ser meramente descritiva, mas, principalmente, argumentativa. Nesse sentido, a autora afirma a predominância dos participantes da pesquisa em relação ao objeto de estudo. Isso implica inserir na análise dos dados um olhar acurado do pesquisador, considerando os depoimentos integrados a um contexto maior. Implica, ainda, que o pesquisador se compreenda como parte de um movimento inacabado e que consiga evidenciar aspectos que ficam em segundo plano.

Ressaltamos que todos os participantes assinaram o Termo de Consentimento Livre e Esclarecido, bem como que o projeto relativo a essa pesquisa foi submetido à Plataforma Brasil para análise ética, tendo sido aprovado pelo Comitê de Ética do Centro de Estudos Superiores de Maceió (CESMAC).

\section{Resultados e Discussão}

Precipuamente apresentamos o perfil dos participantes da pesquisa. O grupo é constituído por 54,2\% (13 participantes) do gênero masculino e 45,8\% (11 participantes) do gênero feminino, com idades que variam entre 24 e 48 anos. Com relação ao grau de instrução, $63 \%$ (15) do segmento possui pós-graduação, dentre esses apenas um (1) técnico possui formação em nível de mestrado. Outros $25 \%$ (6) possuem graduação e $12 \%$ (3) estão cursando o nível superior. No tocante à função que desempenham no Ifal, as respostas dão conta de que o campus dispõe de uma estrutura pedagógica e administrativa que favorece a consolidação de práticas inclusivas, na medida em que conta com profissionais formados nas mais diversas áreas: Assistente de alunos, Assistente Social, Enfermeiro, Pedagogo, Psicólogo, Nutricionista, Técnico em Assuntos Educacionais, Bibliotecário, entre outros. Os técnicos administrativos, no exercício de tais funções, podem e devem fazer parte de um projeto educacional coletivo e colaborativo no Campus, tendo como objetivo a quebra de barreiras que se impõem à profícua inclusão escolar. Essas barreiras, pelo óbice que representam para o gozo de direitos sociais como a educação, devem ser sistematicamente eliminadas por todos os profissionais da educação.

Procedemos a partir de agora à análise dos dados, balizados pela análise qualitativa. Na Questão 1 perguntamos aos participantes da pesquisa se haviam tido alguma experiência com pessoas com deficiência (PcD) e, se sim, em qual situação, conforme Gráfico 1: 
Gráfico 1 - Experiência dos Técnicos Administrativos com Pessoas com Deficiência
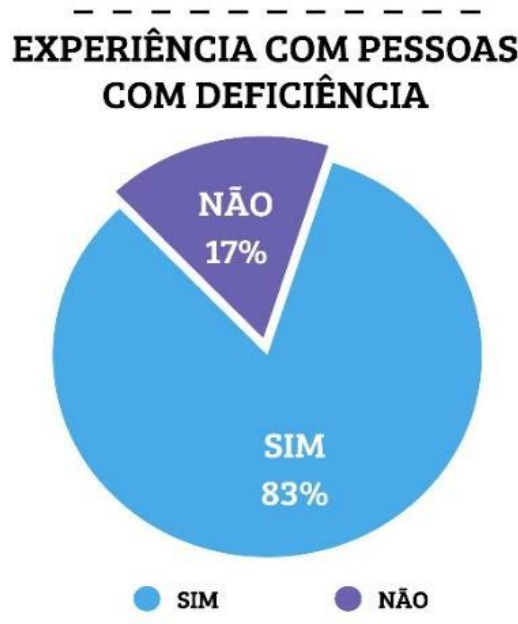
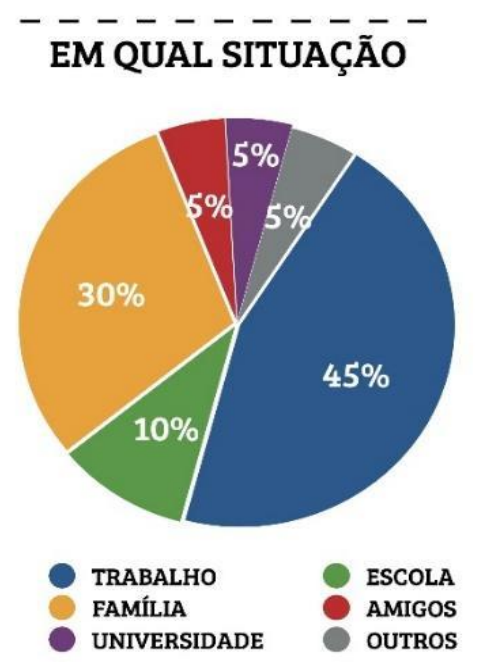

Fonte: Dados da pesquisa (2020).

Conforme Gráfico 1, 83\% (20) dos técnicos administrativos afirmaram ter vivido alguma experiência com $\mathrm{PcD}$, ante os $17 \%$ (4) que indicaram inexperiência com essa realidade. Dentre os que já conviveram com $\mathrm{PcD}$, a maioria deles $(45 \%)$ declarou que suas experiências ocorreram no trabalho; outros $30 \%$ afirmaram que a vivência ocorreu na família e $10 \%$ na escola, dentre outras. Conforme depreende-se, uma maioria significativa dos participantes tiveram experiências com PcD. E mais, os dados mostram que a maior parte dessas experiências $(45 \%)$ ocorreram no trabalho. Tais informações apresentam a escola enquanto lugar privilegiado para a construção de culturas inclusivas que envolvem, sobretudo, "propostas para a construção de uma comunidade escolar segura, receptiva, colaboradora e estimulante em que todos são considerados importantes para a remoção de barreiras para a aprendizagem e para a participação" (PARANÁ, 2006, p. 9).

Essa análise pressupõe a criação de espaços formativos para refletir, junto aos profissionais técnicos-administrativos, a adoção de "medidas inclusivistas" na instituição Sassaki (1997). Ademais, importam ainda as experiências vivenciadas na família (30\%) e na escola (10\%), tendo em vista que a inclusão da pessoa com deficiência não se limita à dimensão educacional, mas é uma questão, sobretudo, social. Sob essa perspectiva, identificamos nesses profissionais, a partir da internalização de conhecimentos teóricos e práticos, canais multiplicadores de ações inclusivas em âmbito institucional e social. Na Questão 2 inquirimos os participantes da pesquisa sobre o que entendem por deficiência, consoante respostas dispostas no Quadro 1:

Quadro 1 - O que você entende por deficiência?

\begin{tabular}{|c|c|}
\hline Participante & Excerto/Depoimento \\
\hline T7 & "Uma necessidade física específica de determinado indivíduo". \\
\hline T9 & $\begin{array}{c}\text { "De modo geral é a ausência parcial ou completa de uma função, por exemplo motora ou } \\
\text { intelectual, ou a falta ou diminuição de determinada substância no organismo". }\end{array}$ \\
\hline T11 & "Ausência de algo". \\
\hline
\end{tabular}

Fonte: Dados da pesquisa (2020). 
Tendo como objetivo a análise das respostas concedidas, recorremos à Lei 13.146/15 (Estatuto da Pessoa com Deficiência), que define o conceito de deficiência:

Art. $2^{\circ}$ Considera-se pessoa com deficiência aquela que tem impedimento de longo prazo de natureza física, mental, intelectual ou sensorial, o qual, em interação com uma ou mais barreiras, pode obstruir sua participação plena e efetiva na sociedade em igualdade de condições com as demais pessoas. (BRASIL, 2015, online).

A partir das informações que constam no Quadro 1, identificamos, por meio dos excertos, que a fala de alguns participantes se distanciam da conceituação de deficiência expressa pelo Estatuto. As respostas dos participantes não comportam a abrangência que o vocábulo deficiência reflete, à luz das diretrizes legais. Nesse sentido, a inserção dos técnicos administrativos, em ações formativas a favor da inclusão, apresenta-se como uma possibilidade para subsidiar a ampliação de conhecimentos teóricos e práticos que circundam o universo das pessoas com deficiência, contribuindo para a qualificação e o aprimoramento de práticas pedagógicas inclusivas. Perguntamos na questão três o que os participantes entendiam por inclusão, conforme Quadro 2:

Tabela 2 - O que você entende por inclusão?

\begin{tabular}{|c|c|}
\hline Participante & Excerto/Depoimento \\
\hline T4 & $\begin{array}{r}\text { "Possibilitar que os sujeitos com as condições específicas possam acessar, dentro do que eles } \\
\text { mesmos entenderem como necessário, rotas também específicas, para o alcance de } \\
\text { objetivos". }\end{array}$ \\
\hline T16 & $\begin{array}{r}\text { "É a garantia de acessibilidade dos estudantes na instituição de ensino, respeitando as } \\
\text { diferenças que cada um apresenta, promovendo meios para sua permaneinal. }\end{array}$ \\
\hline T21 & $\begin{array}{r}\text { um indivíduo a um meio, sem a existência de qualquer tipo de segregação". } \\
\hline\end{array}$ \\
\hline
\end{tabular}

Fonte: Dados da pesquisa (2020).

A análise das respostas expressas na Tabela 2 demonstra que os participantes da pesquisa possuem noções abrangentes e coerentes relativas ao conceito de inclusão. Essa constatação é representativa de benefícios à sociedade, de maneira mais geral, e à comunidade escolar, de maneira mais restrita. Tratam-se de profissionais da educação, com possibilidades para transformação social de práticas excludentes por meio da disseminação de ações e atitudes inclusivas no campus em que atuam. Nessa linha de pensamento, Sassaki (1997) reflete sobre a importância dos conceitos inclusivistas:

Os conceitos são fundamentais para o entendimento das práticas sociais. Eles moldam nossas ações. E nos permitem analisar nossos programas, serviços e políticas sociais, pois os conceitos acompanham a evolução de certos valores éticos, como aqueles em torno da pessoa portadora de deficiência. Portanto, é imprescindível dominarmos bem os conceitos inclusivistas para que possamos ser participantes ativos na construção de uma sociedade que seja realmente para todas as pessoas, independentemente de sua 
cor, idade, gênero, tipo de necessidade especial e qualquer outro atributo pessoal. (SASSAKI, 1997, p. 27).

Embora os participantes demonstrem conhecimento prévio sobre a temática, o domínio conceitual não garante por si só a efetiva participação dos técnicos em práticas educativas que convirjam para uma transformação social no sentido da inclusão. A participação desses profissionais da educação em eventos, ações, palestras e núcleos, promovidos pelas instituições e destinados à sistematização de iniciativas a favor da inclusão, conduz à ampliação dos conhecimentos para além da dimensão conceitual, mas também atitudinal e valorativa, visando à consolidação de novas posturas, assim como a mudança de pensamentos e comportamentos. $\mathrm{Na}$ Questão 4 inquirimos os participantes sobre o que entendiam por educação inclusiva, conforme Quadro 3:

Quadro 3 - O que você entende por educação inclusiva?

\begin{tabular}{|c|c|}
\hline Participante & Excerto/Depoimento \\
\hline $\mathrm{T} 2$ & $\begin{array}{c}\text { "Uma educação que proporcione o acesso e a permanência em condições de igualdade e que } \\
\text { respeita a diversidade". }\end{array}$ \\
\hline $\mathrm{T} 4$ & $\begin{array}{c}\text { "Possibilitar que o/a estudante sinta-se acolhido no sentido físico (acessibilidade na } \\
\text { instituição) e no sentido humano (profissionais capacitados, para entender que tais sujeitos } \\
\text { não são melhores nem piores, mas diferentes). Assim, trata-se de garantir a autonomia aos } \\
\text { referidos sujeitos, ouvindo-os e os respeitando". }\end{array}$ \\
\hline $\mathrm{T} 21$ & $\begin{array}{l}\text { "Entendo se tratar de um modelo de educação na qual não haja segregação e que se garantam } \\
\text { formas de participação e aprendizado equitativas para qualquer indivíduo independente de } \\
\text { qualquer característica que ele possa apresentar". }\end{array}$ \\
\hline
\end{tabular}

Fonte: Dados da pesquisa (2020).

Com o objetivo de analisar as respostas, tomamos como aporte a conceituação referida por Silva e Santos (2019, p. 49): "a inclusão educacional supõe o acolhimento de todas as pessoas de forma ativa e participativa, independente da deficiência, gênero, etnia, religião e as demais parcelas que formam a nossa sociedade". De acordo com os depoimentos registrados na tabela 3, percebemos na fala de alguns participantes a consciência do significado da inclusão educacional. São definições contundentes e pertinentes à temática e que representam um passo importante à inserção desses profissionais nas práticas cotidianas de inclusão. Entretanto, o fato de apresentarem noções conceituais coerentes sobre a temática não é suficiente para garantir a participação efetiva desses profissionais num projeto educacional coletivo e colaborativo, que se redimensiona para reconhecer as possibilidades de inclusão em cada instância administrativa e pedagógica. Nesse viés, Paulon et al. (2005) analisam que:

A apropriação de alguns conceitos é fundamental, contudo, é necessário articular esses conceitos com as situações vividas em cada realidade escolar e na experiência de cada profissional da educação. Este trabalho de articulação é um processo cotidiano e sistemático. Não acontece de uma vez por todas, podendo se dar somente através da análise da vivência de cada profissional em seu fazer diário. Caso não se leve em conta o caráter processual da formação desses profissionais, corre-se o risco de desprezar o conhecimento e a experiência prévia que cada um traz consigo. (PAULON et al. 2005, p. 21). 
Isso posto, ressaltamos a necessidade de formação relativa à temática para a categoria, a fim de promover mudanças nos aspectos de sensibilização e acessibilidade na instituição, contribuindo, assim, para que os técnicos administrativos passem a ser parte integrante do processo de inclusão. Na Questão 5 indagamos se os participantes já haviam recebido formação em educação inclusiva, conforme demonstra o Gráfico 2.

Gráfico 2 - Participação dos Técnicos Administrativos em formação inclusiva

\section{PARTICIPAÇÃO EM FORMAÇÃO SOBRE A TEMÁTICA INCLUSIVA}

SIM
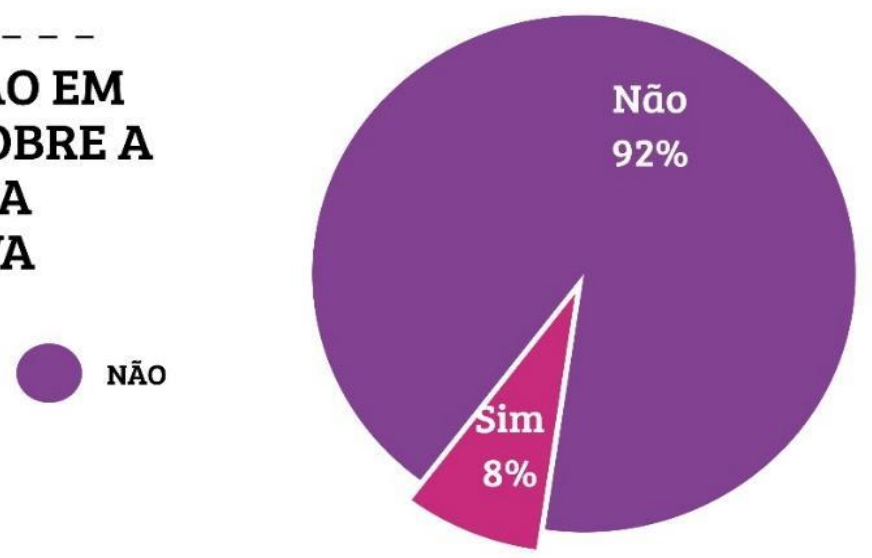

Fonte: Dados da pesquisa (2020).

A análise do gráfico reforça a demanda de ações e propostas formativas destinada à categoria, uma vez que de, um universo de 24 técnicos administrativos, apenas dois (8\%) afirmaram já ter recebido formação em relação à temática, um dado problemático diante do fato de que esses profissionais devem compor a estrutura do NAPNE, órgão responsável pela direção das políticas inclusivas na instituição. E desses dois, apenas o participante T2 afirma ter recebido formação no trabalho, tendo relatado essa experiência:

\footnotetext{
Foi muito bom. Depois de ter feito minha especialização, minha forma de enxergar as pessoas com algum tipo de deficiência mudou totalmente. Antes, assim como a maioria das pessoas, era levada a ter um pouco de pena, vendo como "coitadinho", mas ao ter contato com surdos, por exemplo, vi o quão capazes são, basta ser-lhe dada oportunidade. As pessoas com deficiência têm suas limitações e potenciais como quaisquer outras pessoas, tudo pode ser desenvolvido através da prática, das oportunidades. Muitos dos problemas que muitas pessoas com deficiência enfrentam não estão nelas mesmas, mas no que a sociedade (que não foi educada historicamente e culturalmente) impõe, excluindo-os ao vê-los como pessoas incapazes de se relacionarem e de exercerem certas funções, não cogitando qualquer adaptação (nem se lembram de que as pessoas de um modo geral precisam sempre estarem se adaptando às circunstâncias da vida). (T2, Dados da Pesquisa, 2020).
}

O excerto constante no depoimento do participante T2 indica a necessidade de formação em educação inclusiva para todos os trabalhadores em educação, gestores, docentes e técnicos administrativos. Quando se trata de inclusão, o que importa antes de tudo é a consciência de que essa é uma responsabilidade ética, política e social. Logo, enquanto trabalhadores em 
educação, é fundamental que todos possam contribuir para que a escola cumpra sua função de assegurar aos alunos com NEE o direito a uma educação mais justa, democrática e solidária.

Todavia, Paulon et al. (2005, p. 21) advertem que "para operar as transformações nos modos de relação dentro da escola é, também, necessário que os profissionais envolvidos tomem para si a tarefa de pensar estas questões de forma reflexiva e coletiva". Assim sendo, faz-se necessário fomentar ações focadas na sensibilização e desmistificação da problemática da inclusão numa perspectiva que exorbite a sala de aula e atenue a responsabilidade que paira somente sobre o professor, sendo compartilhada por todos os agentes educativos para mudança de atitudes, num processo contínuo e permanente no âmbito institucional. Considerando que as produções acadêmicas e a literatura especializada em educação inclusiva destinam-se, em sua maioria, à formação docente, ressaltamos a necessidade e a importância de formação para os técnicos administrativos, visando à efetiva participação nas instâncias promotoras de ações e políticas de inclusão. A ausência de formação para esse segmento que compõe a instituição pode ser a causa das respostas vagas e imprecisas quando perguntamos qual deve ser o papel do técnico no processo de inclusão, conforme demonstra o Quadro 4:

Quadro 4 - Qual deve ser o papel do técnico no processo de inclusão?

\begin{tabular}{|c|c|}
\hline Participante & Excerto/Depoimento \\
\hline T7 & "Contribuir para a sua efetivação". \\
\hline T11 & "Auxiliar os profissionais nesse processo". \\
\hline T14 & "Estudar e aplicar formas de inclusão". \\
\hline
\end{tabular}

Fonte: Dados da pesquisa (2020).

A inclusão dos estudantes com NEE, no contexto da EPT, passa por uma vista dilatada dos atores sociais que circundam as práticas educativas. Desse modo, o exercício social e profissional do técnico administrativo em educação torna-se imprescindível à adoção de uma nova cultura institucional, na qual esse agente compromete-se com os fins educacionais, abdicando de um olhar limitante que o remete a ser apenas meio para a consecução dos objetivos institucionais. Mas de que maneira viabilizar esse processo, no qual o servidor técnicoadministrativo vincula suas atividades ao objetivo institucional de promover a inclusão em todos os seus espaços?

O conhecimento, a sensibilização e a participação no Núcleo de Apoio às Pessoas com Necessidades Específicas (NAPNE) apresentam-se como caminho que conduz a essa direção. O significado da palavra núcleo remete a algo que é central, essencial. Assim sendo, dentro da estrutura organizacional do Ifal, o NAPNE é a instância central onde são sistematizadas e articuladas as ações e políticas para atender às necessidades educacionais dos alunos, oferecendo suporte para o trabalho pedagógico do professor. No entanto, a atuação desse Núcleo fica comprometida a partir da não adesão por parte de todos os agentes da instituição, pois consoante pontuam Soares e Fortes (2019, p. 33): "O NAPNE deve ser composto por profissionais de diferentes áreas, sendo servidores do próprio quadro efetivo de cada Instituto, o que facilita uma visão multidisciplinar das situações e necessidades de adaptação para atendimento dos alunos". A partir desse entendimento, perguntamos aos participantes da pesquisa se conheciam o NAPNE, em conformidade com o Gráfico 3: 
Gráfico 3 - Conhecimento dos Técnicos Administrativos sobre a atuação do NAPNE

\section{CONHECIMENTO DOS TAE'S ACERCA DO NAPNE}
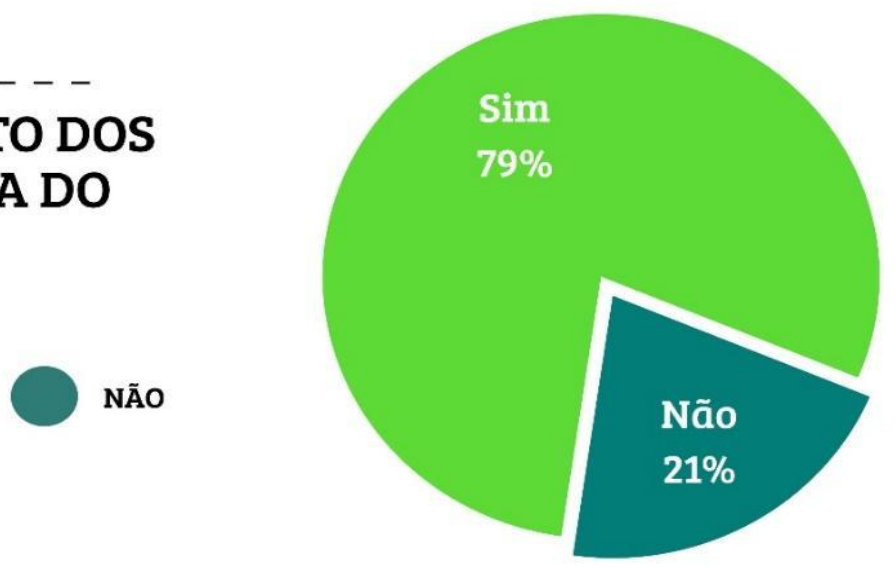

Fonte: Dados da pesquisa (2020).

A observação do gráfico indica que, num universo de apenas 24 técnicos, cinco (21\%) responderam que não conhecem, um número considerável, tendo em vista a importância dessa instância dentro de cada Instituto Federal na promoção de ações inclusivas. Dentre as atribuições do NAPNE consta, inclusive, "a promoção de eventos que promovam a sensibilização da comunidade acadêmica e capacitação de servidores em geral" (Ifal, 2014). Ainda nessa linha de raciocínio, perguntamos aos participantes qual seria a função do NAPNE, conforme excertos dos depoimentos no Quadro 5:

Quadro 5 - Qual a função do NAPNE?

\begin{tabular}{|c|c|}
\hline Participante & Excerto/Depoimento \\
\hline T6 & "Dar suporte especializado aos portadores de necessidades específicas". \\
\hline T12 & "Conheço superficialmente, é um núcleo que trata de assuntos relacionados às pessoas \\
portadoras de deficiências".
\end{tabular}

Fonte: Dados da pesquisa (2020).

Os excertos dos depoimentos evidenciam que o conhecimento dos técnicos em relação ao NAPNE é superficial e não abrange as suas competências e atribuições. $\mathrm{O}$ fato de esses profissionais não estarem diretamente ligados ao ensino, não deve representar um obstáculo para sensibilização e conscientização em relação ao seu papel diante da inclusão. A desmistificação de uma educação inclusiva restrita à sala de aula é condição imprescindível para atenuar o peso da responsabilidade imposta ao professor, que passa a dispor de uma equipe de apoio para dar suporte e garantir que o aluno com NEE tenha seu direito de inclusão garantido, não apenas em imperativos e discursos, mas no cotidiano da instituição, em todos os espaços e nas relações estabelecidas com seus diversos atores. Assim, cada um dos profissionais 
em educação, dentro de sua área de formação, função e experiência pode deixar-se envolver e, nas palavras de Soares e Fortes (2019, p.32), "contribuir e intervir de forma a ampliar as possibilidades de efetiva inclusão de cada aluno atendido".

Nessa perspectiva, entendemos que o papel dos técnicos administrativos deve-se somar ao de docentes e gestores para promover uma educação inclusiva de qualidade. Para tanto, o conhecimento, a sensibilização e a participação no NAPNE, bem como em momentos formativos envolvendo a temática da inclusão da pessoa com deficiência dentro e fora do campus, são condições imprescindíveis, a fim de compreender os limites e as possibilidades impostas cotidianamente aos alunos com NEE, assumindo novas atitudes e posturas relativas à inclusão. Indagamos aos participantes da pesquisa se acreditam que existe educação inclusiva no Ifal, conforme Gráfico 4:

Gráfico 4 - Percepção dos Técnicos Administrativos sobre a garantia de educação inclusiva no Ifal

\section{GARANTIA DE EDUCAÇÃO INCLUSIVA NO IFAL}

SIM
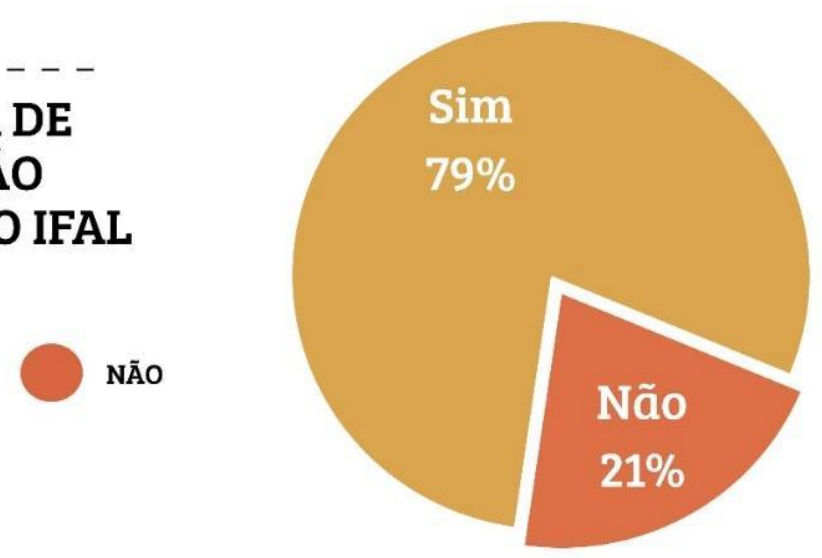

Fonte: Dados da pesquisa (2020).

A análise desses dados nos mostra que, enquanto 79\% (19) dos técnicos acreditam que existe educação inclusiva no Ifal, $21 \%$ (5) discordam dessa premissa. Têm-se nesse caso elementos positivos e negativos. $\mathrm{O}$ fato de a maioria dos técnicos demonstrarem consciência de que o Ifal assume o compromisso perante a inclusão e implementa políticas nessa perspectiva é importante, na medida em que reconhecem que essa responsabilidade também os compete e que, portanto, precisam inteirar-se e envolver-se com a promoção de ações e iniciativas nesse sentido. Todavia, a situação contrária indica a necessidade de inserção desses profissionais da educação, nos debates e ações desenvolvidos em favor da inclusão, tendo em vista que em um universo de 24, relativamente diminuto, cinco servidores técnicos ainda não acreditam ou desconhecem que o Ifal propõe uma política de educação inclusiva. Perguntamos aos participantes da pesquisa por quais motivos eles acreditam que existe educação inclusiva no Ifal, como mostra o Quadro 6: 
Quadro 6 - Existe educação inclusiva no Ifal?

\begin{tabular}{|c|c|c|c|}
\hline \multicolumn{2}{|c|}{ Creem que o Ifal é inclusivo } & \multicolumn{2}{c|}{ Não creem que o Ifal é inclusivo } \\
\hline Participante & Excerto/Depoimento & Participante & Excerto/Depoimento \\
\hline T1 & $\begin{array}{c}\text { "O Ifal é um instituto que } \\
\text { valoriza e respeita a diversidade. } \\
\text { Constantemente desenvolve ações } \\
\text { voltadas para a inclusão de todos } \\
\text { os alunos e sua formação para a } \\
\text { vivência em sociedade". }\end{array}$ & T4 & $\begin{array}{c}\text { "Porque a educação inclusiva não pode } \\
\text { se limitar ao atendimento imediato de } \\
\text { um caso, mas deve ter como pilar toda } \\
\text { uma preparação da comunidade escolar. } \\
\text { Há que se debater o tema com todos os } \\
\text { discentes e profissionais, o que, } \\
\text { atualmente, não acontece". }\end{array}$ \\
\hline $\begin{array}{c}\text { T3 } \\
\text { "Acredito que há uma busca por } \\
\text { uma educação inclusiva através } \\
\text { de diversas ações de inclusão: as } \\
\text { cotas, a política de assistência } \\
\text { estudantil, os NAPNEs". }\end{array}$ & T8 & $\begin{array}{c}\text { "Ainda é preciso melhorar muito. Ter } \\
\text { um campus adaptado não é por si só } \\
\text { efetivo, mas também deve-se ter } \\
\text { aplicado outros métodos de inclusão } \\
\text { sobretudo às aulas em sala e campo". }\end{array}$ \\
\hline
\end{tabular}

Fonte: Dados da pesquisa (2020).

Os depoimentos na Tabela 6 revelam, de um lado, a consciência daqueles que creem haver inclusão e a necessidade de direcionar suas atividades profissionais para um projeto educacional coletivo e colaborativo no campus em que atuam, de outro, a descrença ou o desconhecimento de alguns técnicos em relação às políticas de inclusão. Diante do exposto, questionamos os participantes da pesquisa sobre como percebem a oferta de formação em educação inclusiva, de modo que cem (100\%) dos técnicos administrativos reconhecem a importância da aludida formação para a garantia da inclusão no ambiente escolar.

\section{Considerações Finais}

O debate acerca da inclusão insere-se em um contexto não apenas educacional, mas também ético, político e social. Nessa perspectiva, compreendemos que a responsabilidade pela inclusão de alunos com NEE, no âmbito da EPT, que tem como objetivo a formação integrada do sujeito, precisa ser compartilhada por todos os segmentos da comunidade educacional, incluindo aqueles que não estão diretamente vinculados ao ensino. Nesse caso, convém oportunizar aos técnicos administrativos a participação ativa no processo de inclusão no ambiente escolar, a fim de contribuírem para o acolhimento, a orientação, a comunicação, o desenvolvimento de novas posturas relativas à inclusão, à quebra de barreiras das mais diversas naturezas, entre outros limites e possibilidades que se impõem cotidianamente ao estudante com NEE.

Ressaltamos a importância desses profissionais, enquanto atores sociais relevantes para a construção dos valores disseminados no ambiente escolar, de tal modo que suas práticas podem somar-se às dos demais profissionais, a exemplo de docentes e gestores, visando à consolidação de um projeto educacional inclusivo, que transcenda a sala de aula e a relação professor-aluno para acontecer em todos os espaços e nas interações com todos os que compõem as instâncias administrativas e pedagógicas da instituição.

Partimos do pressuposto de que o alcance de um projeto educativo de natureza inclusiva pressupõe sensibilização, preparação e tomada de consciência por parte de todos os agentes implicados no processo de formação dos alunos com NEE. Para tanto, o exercício profissional e social dos técnicos administrativos deve vincular-se a um projeto institucional de ações 
coletivas que se complementam para aproximar-se, tanto quanto possível, de uma educação, de fato, inclusiva. Concluímos que existe carência de produções acadêmicas, bem como espaços de diálogos e de formação em educação inclusiva, destinados à preparação e sensibilização dos técnicos administrativos em educação. A partir dessa circunstância, assistimos a um processo de invisibilização dos técnicos administrativos em relação ao movimento da inclusão, cujas consequências são a participação restrita e a irrelevância do papel desempenhado por esses profissionais frente à construção de práticas educativas inclusivas.

O escopo desse trabalho não tem a pretensão de responder ou esgotar todas as possibilidades em relação à temática, oferecendo tão somente um debate introdutório, que insere os técnicos administrativos no processo de inclusão e sinaliza a necessidade de que as instituições executem uma política de formação que inclua esse segmento, contribuindo, dessa forma, para ampliar as concepções e percepções desses profissionais em relação ao universo dos alunos com NEE.

\section{Referências}

BRASIL. Lei $\mathbf{n}^{0}$ 11.091, de 12 de janeiro de 2005. Dispõe sobre a estruturação do Plano de Carreira dos Cargos Técnico-Administrativos em Educação, no âmbito das Instituições Federais de Ensino vinculadas ao Ministério da Educação, e dá outras providências. Brasília, 2005. Disponível em:

https://www.ifb.edu.br/attachments/article/6389/Lei\%2011.091_2005.pdf. Acesso em: 21 jul. 2020.

BRASIL. Lei no $\mathbf{1 1 . 8 9 2}$, de 29 de dezembro de 2008. Institui a Rede Federal de Educação Profissional, Científica e Tecnológica, cria os Institutos Federais de Educação, Ciência e Tecnologia, e dá outras providências. Diário Oficial da União, Seção 1, p. 1, 30 dez. 2008.

BRASIL. Lei 12.711, de 29 de agosto de 2012. Dispõe sobre o ingresso nas Universidades Federais e nas Instituições Federais de ensino técnico de nível médio e dá outras providências. Brasília, 2012. Disponível em: http://www.planalto.gov.br/ccivil_03/_ato20112014/2012/lei/112711.htm. Acesso em: 08 jul. 2020.

BRASIL. Lei 13.146, de 6 de julho de 2015. Institui a Lei Brasileira de Inclusão de Pessoas com Deficiência (Estatuto da Pessoa com Deficiência). Brasília, 2015. Disponível em: http://www.planalto.gov.br/ccivil_03/_ato2015-2018/2015/lei/113146.htm. Acesso em: 21 jul. 2020.

CIAVATTA, M.; RAMOS M. Ensino Médio e Educação Profissional no Brasil: dualidade e fragmentação. Revista Retratos da Escola, Brasília, v. 5, n. 8, p. 27-41, jan./jun. 2011.

INSTITUTO FEDERAL DE EDUCAÇÃO, CIÊNCIA E TECNOLOGIA DE ALAGOAS. Projeto Político Pedagógico Institucional. Maceió, Ifal, 2013. Disponível em: http://www.reditec.Ifal.edu.br/portal/Ifal/reitoria/conselho-superior 1/resolucoes/2013/PPP\%20APROVADO\%20DIAGRAMADO_21_02.pdf/view. Acesso em: 19 jun. 2020.

INSTITUTO FEDERAL DE EDUCAÇÃO, CIÊNCIA E TECNOLOGIA DE ALAGOAS. Resolução no 45-CS-2014. Maceió: Ifal, 2014. Disponível em: https://www2.Ifal.edu.br/oIfal/ensino/legislacao-e-normas/arquivos-legislacao/direcao-de-politicas-estudantis/resolucao- 
no-45-cs-2014-napne-Ifal-regulamento.pdf/view. Acesso em: 05 jun. 2020.

INSTITUTO FEDERAL DE EDUCAÇÃO, CIÊNCIA E TECNOLOGIA DE ALAGOAS. Regulamento Interno do Conselho Superior. Maceió: Ifal, 2016. Disponível em: https://www2.Ifal.edu.br/o-Ifal/institucional/orgaos-colegiados/conselhosuperior/arquivos/regimento-interno-do-conselho-superior-do-Ifal-alterado-pela-res-no-22-acs-2016-2.pdf. Acesso em: 19 jun. 2020.

LÜDKE, M.; ANDRÉ, M. E. D. A. Pesquisa em educação: abordagens qualitativas. São Paulo: EPU, 1986.

MINAYO, M. C. S. Análise qualitativa: teoria, etapas e fidedignidade. Ciência \& Saúde Coletiva, Rio de Janeiro, v. 17, n. 3, p. 621-626, mar. 2012. Disponível em: https://www.scielo.br/j/csc/a/39YW8sMQhNzG5NmpGBtNMFf/?lang=pt Acesso em: 19 jul. 2020.

NAVARRO, I. P. et al. Conselho escolar e a valorização dos trabalhadores em educação. Brasília: MEC, 2006.

PARANÁ. Secretaria de Estado da Educação. Diretrizes curriculares estudos temáticos para o Plano Estadual de Educação do Paraná: resultados do I Seminário Integrador. Curitiba: Secretaria da Educação, 2006.

PAULON, S. M. et al. Documento subsidiário à política de inclusão Gerson Smiech Pinho. Brasília: Ministério da Educação, Secretaria de Educação Especial, 2005.

RAMOS, M. Concepção do ensino médio integrado. MIMEO. Pará: Secretaria de Estado da Educação, 2008.

SASSAKI, R. K. Inclusão - construindo uma sociedade para todos. Rio de Janeiro: WVA, 1997.

SAVIANI, Dermeval. O choque teórico da Politecnia. Trabalho, Educação e Saúde, Rio de Janeiro, v. 1, n. 1, p. 131-152, mar. 2003. Disponível em: http://www.scielo.br/scielo.php?script=sci_arttext\&pid=S1981-

77462003000100010\&lng=en\&nrm=iso. Acesso em: 21 set. 2020.

SILVA, A. R. da; SANTOS, G. C. Silva. A gestão pedagógica e o processo de inclusão educacional de alunos cegos: um estudo de caso. In: WESSELOVICZ, G.; CAZINI, J. (orgs.). Diálogos sobre inclusão. Ponta Grossa: Atena, 2019.

SOARES, A. de A.; FORTES, K. P. da S. A educação inclusiva com foco na pessoa com deficiência: possibilidades de atuação do NAPNE. In: WESSELOVICZ, G.; CAZINI, J. (orgs.). Diálogos sobre inclusão. Ponta Grossa: Atena, 2019.

Recebido em junho de 2021.

Aprovado em outubro de 2021. 